\title{
Central and Peripheral Response to Incremental Cycling Exercise in Older Untrained Active Men: A Comparison of Those In-Between
}

\author{
C. D. O'NEILL ${ }^{1}$, D. S. KIMMERLY ${ }^{2}$, S. DOGRA ${ }^{1}$ \\ ${ }^{1}$ Faculty of Health Sciences (Kinesiology), University of Ontario Institute of Technology, Oshawa, \\ ON, Canada, ${ }^{2}$ School of Health and Human Performance, Kinesiology, Dalhousie University, \\ Halifax, NS, Canada
}

Received April 25, 2015

Accepted July 1, 2015

On-line October 8, 2015

\section{Summary}

The aim of this study was to compare the central and peripheral components of cardiorespiratory fitness during incremental to maximal exercise between older men who were either recreational athletes (RA) or leisurely active (LA) men, i.e., those who fall between trained and untrained. This was a crosssectional study in which all subjects completed an exercise test on a cycle ergometer. Maximal oxygen consumption $\left(\mathrm{VO}_{2 \max }\right)$ and ventilatory threshold (VT) were assessed using gas analysis, and central components of $\mathrm{VO}_{2 \max }$ were assessed using a non-invasive thoracic bio-impedance device. $\mathrm{VO}_{2 \max }$ (RA: $45.1 \pm 4.8 \mathrm{ml} / \mathrm{kg} / \mathrm{min}$; LA: $32.2 \pm 4.6 \mathrm{ml} / \mathrm{kg} / \mathrm{min}, \mathrm{p} \leq 0.001$ ) and SV at maximal exercise (RA: $133.5 \pm 24.96 \mathrm{ml} /$ beat; LA: $107.9 \pm 17.6 \mathrm{ml} /$ beat, $\mathrm{p}=0.005$ ) were higher in the RA group compared to the LA group. A plateau in SV occurred between $30-45 \%$ of maximal exercise capacity in the RA group. No differences in SV were observed across workloads in the LA group. No differences in the calculated arterio-venous oxygen difference $\left((a-v) \mathrm{O}_{2 \text { diff }}\right)$ were observed between groups. In conclusions, training volume appears to influence central components of cardiorespiratory fitness among a matched sample of older men who are neither trained nor untrained. This builds a case for increasing the volume of training to preserve cardiorespiratory fitness among older men.

\section{Key words}

Stroke volume $\bullet$ Aging $\bullet \mathrm{VO}_{2 \max } \bullet$ Fitness

\section{Corresponding author}

C. O'Neill, Faculty of Health Sciences, University of Ontario Institute of Technology, 2000 Simcoe St N, Oshawa, ON, L1H-7K4, Canada. E-mail: carley.oneill@uoit.net

\section{Introduction}

Endurance trained older adults have higher maximal cardiac output (Q), stroke volume (SV), and arterio-venous oxygen difference $\left((\mathrm{a}-\mathrm{v}) \mathrm{O}_{2 \text { diff }}\right)$ compared to untrained older adults (McLaren et al. 1997). While it is generally accepted that SV plateaus at 40-50\% of maximal exercise capacity (Astrand et al. 1964), there is some research to suggest that highly trained individuals may have a continuous increase in SV to maximal exercise (Rivera et al. 1989). Such research has typically compared highly trained older adults $\left(\mathrm{VO}_{2 \max }>50 \mathrm{ml} / \mathrm{kg} / \mathrm{min}\right)$ to untrained/sedentary older adults $\left(\mathrm{VO}_{2 \max }<30 \mathrm{ml} / \mathrm{kg} / \mathrm{min}\right)$ (Rivera et al. 1989, Dogra et al. 2012). The central and peripheral response of recreationally active older adults that fall in between these extremes of trained and untrained is not well described. Specifically, the cardiovascular exercise response profile of older men who are recreational athletes (RA) or simply leisurely active (LA) is not known.

Thus, the purpose of this study was to describe the cardiovascular response of older active men, who are neither highly trained nor completely sedentary, to incremental maximal cycling exercise. It was hypothesized that RA would have a similar response as that previously observed in highly trained older men, and that the RA would exhibit greater cardiovascular health than the LA.

\section{Materials and Methods}

\section{Study design and subjects}

Inclusion in this cross-sectional study was 
limited to males aged 60-80 years without any chronic cardiovascular or respiratory conditions. Subjects were recruited from local cycling groups. They completed a training $\log$ (7 day recall) prior to testing and were divided into RA or LA based on this recall. Subjects were considered RA if they were participating in moderatevigorous cycling for a minimum of one hour 3-4 times per week. Subjects were considered LA if they were meeting the minimum recommendations of $150 \mathrm{~min} /$ week of moderate to vigorous physical activity (Paterson and Warburton 2010). A total of 36 older men were screened for participation; two subjects declined further participation and four were considered ineligible due to age and cardiovascular health impairments. Two subjects were excluded from analysis due to technological difficulties during testing, resulting in unusable data. No subjects were taking any medications that would affect cardiovascular response to exercise. All subjects were pre-screened to ensure they were at minimal risk for participation in the exercise testing and all subjects provided written informed consent prior to laboratory testing (Canadian Society of Exercise Physiology 2013). All procedures were approved by the Research Ethics Boards of Acadia University and the University of Ontario Institute of Technology.

\section{Methodology}

Subjects attended one laboratory session. Familiarization to the mode of exercise was not necessary as all subjects were regularly cycling. Anthropometric measures of height, weight, and waist circumference were assessed using a standard medical scale and a tape measure to the nearest $0.5 \mathrm{~cm}, 0.1 \mathrm{~kg}$ and $0.1 \mathrm{~cm}$ respectively. Body mass index (BMI) was calculated as weight $(\mathrm{kg}) /$ height $^{2}(\mathrm{~m})$. Resting heart rate and blood pressure were measured manually after resting in a seated position for $5 \mathrm{~min}$. Blood pressure was recorded manually a total of three times. Measurements were entered into the software prior to and following calibration as per Physioflow instructions. Subjects were then fitted with electrodes and connected to a noninvasive thoracic electric bio-impedance device (Physioflow Enduro, Bristol, PA, USA). Resting measures of Q and SV were recorded for up to $2 \mathrm{~min}$ after sitting quietly for $3 \mathrm{~min}$.

Subjects then completed a maximal exercise test on a cycle ergometer (LODE Excalibur, Lode BV, Groningen, The Netherlands) using a ramp incremental protocol $(25 \mathrm{~W} / \mathrm{min})$. Subjects maintained a self-selected pace between 70-100 revolutions per minute. Maximal oxygen consumption $\left(\mathrm{VO}_{2 \max }\right)$ was determined by a plateau in $\mathrm{VO}_{2}$ and confirmed by a respiratory exchange ratio higher than 1.1, achievement of age-predicted maximum heart rate $(220$ - age), a rating of perceived exertion above 19 (scale of 6-20), and/or volitional exhaustion.

\section{Gas exchange measurements}

Expired $\mathrm{CO}_{2}$ and $\mathrm{O}_{2}$ were collected through a pneumotachograph (Hans Rudolph 2700) and were analyzed using a gas collection system (Parvo Medics OUSW 4.3, USA) at five-second intervals (to align with the impedance cardiography output). $\mathrm{VO}_{2 \max }$ was recorded as an average of the highest 25 s period (i.e. 5 data points). The first ventilatory threshold (VT) was visually determined independently by two researchers as the point where ventilation increased non-linearly to the increase in $\mathrm{O}_{2}$ uptake and by identifying the point at which $\mathrm{CO}_{2}$ production increased at a faster rate than $\mathrm{VO}_{2}$.

\section{Central and peripheral components of $\mathrm{VO}_{2}$}

Heart Rate (HR), SV, end diastolic volume (EDV), early diastolic filling ratio (EDFR) and Q were measured at $5 \mathrm{~s}$ intervals non-invasively using thoracic electric bio-impedance signals. The Physioflow uses changes in transthoracic impedance during cardiac ejection to calculate SV (Charloux et al. 2000) via highfrequency and low-amperage alternating electric current from six electrodes. The accuracy and reproducibility of the Physioflow has been assessed in normal-weight and overweight participants during an incremental to maximal exercise test against the direct Fick method (Richard et al. 2001). The mean difference between values obtained by the Physioflow was $0.0091 \mathrm{~min}^{-1}$, and the correlation coefficient between the Physioflow and the direct Fick method was $r=0.946$ (Richard et al. 2001). In the present study, the Fick equation was used to calculate (a-v) $\mathrm{O}_{2 \text { diff }}$ as follows: (a-v) $\mathrm{O}_{2 \text { diff }}\left(\mathrm{ml} \mathrm{O}_{2} / 100 \mathrm{ml}\right.$ blood $)=\left[\mathrm{VO}_{2}\right.$ $(1 / \mathrm{min}) / \mathrm{Q}(1 / \mathrm{min})] \times 100$. The Fick equation has been used in previous studies to calculate (a-v) $\mathrm{O}_{2 \text { diff }}$ at rest and during exercise in normal-weight and obese individuals (Vella et al. 2011) and has been deemed to be accurate as per Richard et al. (2001). Measures of $\mathrm{VO}_{2}$ and Q data were time aligned for analysis.

\section{Statistical analyses}

Data in tables are presented as means and standard deviation (SD). Independent samples t-tests were used to compare subject characteristics and $\mathrm{VO}_{2 \max }$ 
parameters between RA and LA. Paired sample t-tests were used to determine differences among parameters during exercise. A repeated measures analysis of variance was used to assess for differences within groups during the incremental exercise test. Data in graphs are presented as means and standard error. All statistics were conducted in SPSS v21 (SPSS Inc., Armonk, NY). Statistical significance was declared at $\mathrm{p}<0.05$.

\section{Results}

RA were cycling $186.9 \pm 22.6 \mathrm{~km}$ per week and training $7.9 \pm 1.5 \mathrm{~h}$ per week. LA were taking part in light to moderate intensity physical activity (e.g. walking, gardening and cycling) $5.6 \mathrm{~h}$ per week. One LA was a smoker. Additional sample characteristics are presented in Table 1. Other than $\mathrm{VO}_{2 \max }$ and resting heart rate, there were no differences between the RA and LA group i.e. they were well matched for age and body composition.
Table 1. Sample characteristics.

\begin{tabular}{|c|c|c|}
\hline \multirow[t]{2}{*}{ Characteristic } & $\begin{array}{c}\text { Recreational } \\
\text { athletes } \\
(n=15)\end{array}$ & $\begin{array}{c}\text { Leisurely } \\
\text { active } \\
(n=13)\end{array}$ \\
\hline & Mean \pm SD & Mean \pm SD \\
\hline Age (years) & $65.4 \pm 3.5$ & $67.6 \pm 4.1$ \\
\hline Weight (kg) & $79.6 \pm 7.3$ & $78.7 \pm 11.5$ \\
\hline Height $(\mathrm{cm})$ & $173.7 \pm 6.1$ & $172.3 \pm 4.7$ \\
\hline $\begin{array}{l}\text { Waist } \\
\text { circumference (cm) }\end{array}$ & $90.3 \pm 6.6$ & $93.4 \pm 8.2$ \\
\hline $\begin{array}{l}\text { Body mass index } \\
\left(\mathrm{kg} \cdot \mathrm{m}^{-2}\right)\end{array}$ & $26.3 \pm 2.1$ & $26.5 \pm 3.5$ \\
\hline $\begin{array}{l}\text { Systolic blood } \\
\text { pressure (mm Hg) }\end{array}$ & $117.0 \pm 8.1$ & $116.2 \pm 8.9$ \\
\hline $\begin{array}{l}\text { Diastolic blood } \\
\text { pressure (mm Hg) }\end{array}$ & $74.0 \pm 9.1$ & $71.8 \pm 5.7$ \\
\hline $\begin{array}{l}\text { Resting heart rate } \\
\text { (beats/min) }\end{array}$ & $57.3 \pm 9.3$ & $64.7 \pm 8.5^{*}$ \\
\hline
\end{tabular}

Data are mean $\pm \mathrm{SD} . * \mathrm{p}<0.05$

Table 2. Cardiovascular parameters from incremental to maximal cycling exercise in recreational athletes $(n=15)$ and leisurely active $(n=13)$ older men.

\begin{tabular}{|c|c|c|c|c|}
\hline \multirow{3}{*}{ Characteristic } & \multicolumn{2}{|c|}{ At ventilatory threshold } & \multicolumn{2}{|c|}{ At maximal exercise } \\
\hline & Recreational athletes & Leisurely active & Recreational athletes & Leisurely active \\
\hline & Mean \pm SD & Mean \pm SD & Mean \pm SD & Mean \pm SD \\
\hline $\mathrm{VO}_{2}(\mathrm{l} / \mathrm{min})$ & $2.6 \pm 0.3$ & $1.8 \pm 0.2 *$ & $3.5 \pm 0.4$ & $2.5 \pm 0.4^{*}$ \\
\hline $\begin{array}{l}\mathrm{VO}_{2} \\
(\mathrm{ml} / \mathrm{kg} / \mathrm{min})\end{array}$ & $34.1 \pm 7.8$ & $23.4 \pm 4.6^{*}$ & $45.1 \pm 4.8$ & $32.2 \pm 4.6^{*}$ \\
\hline $\begin{array}{l}(a-v) O_{2 \text { diff }} \\
\left(\mathrm{ml} \mathrm{O} \mathrm{O}_{2} / 100 \mathrm{ml}\right)\end{array}$ & $14.1 \pm 5.8$ & $12.4 \pm 4.3$ & $16.6 \pm 4.6$ & $14.7 \pm 3.7$ \\
\hline $\begin{array}{l}\text { Heart rate } \\
\text { (beats/min) }\end{array}$ & $138.3 \pm 21.6$ & $130.2 \pm 12.0$ & $156.0 \pm 15.6$ & $150.5 \pm 15.0$ \\
\hline $\begin{array}{l}\text { Stroke volume } \\
(\mathrm{ml} / \text { beat })\end{array}$ & $131.9 \pm 28.7$ & $112.8 \pm 19.9^{\#}$ & $133.5 \pm 24.9$ & $107.9 \pm 17.6^{*}$ \\
\hline $\begin{array}{l}\text { Cardiac output } \\
\text { (l/min) }\end{array}$ & $17.7 \pm 3.5$ & $14.7 \pm 2.6^{*}$ & $20.9 \pm 4.0$ & $16.3 \pm 3.0 *$ \\
\hline Power (W) & $193.3 \pm 46.7$ & $146.4 \pm 30.8^{*}$ & $280.0 \pm 31.6$ & $209.6 \pm 29.8^{*}$ \\
\hline $\begin{array}{l}\text { End diastolic } \\
\text { volume (ml) }\end{array}$ & $213.1 \pm 41.9$ & $176.1 \pm 31.0^{*}$ & $214.9 \pm 33.4$ & $188.1 \pm 38.1^{\#}$ \\
\hline $\begin{array}{l}\text { Early diastolic } \\
\text { filling ratio }\end{array}$ & $74.1 \pm 37.9$ & $75.0 \pm 47.2$ & $81.3 \pm 28.9$ & $80.8 \pm 19.3$ \\
\hline
\end{tabular}

${ }^{*} \mathrm{p}<0.05 ;{ }^{*} \mathrm{p}<0.10$. CI: confidence interval; $\mathrm{VO}_{2}$ : oxygen uptake; $(\mathrm{a}-\mathrm{v}) \mathrm{O}_{2 \text { diff: }}$ arterio-venous oxygen difference 

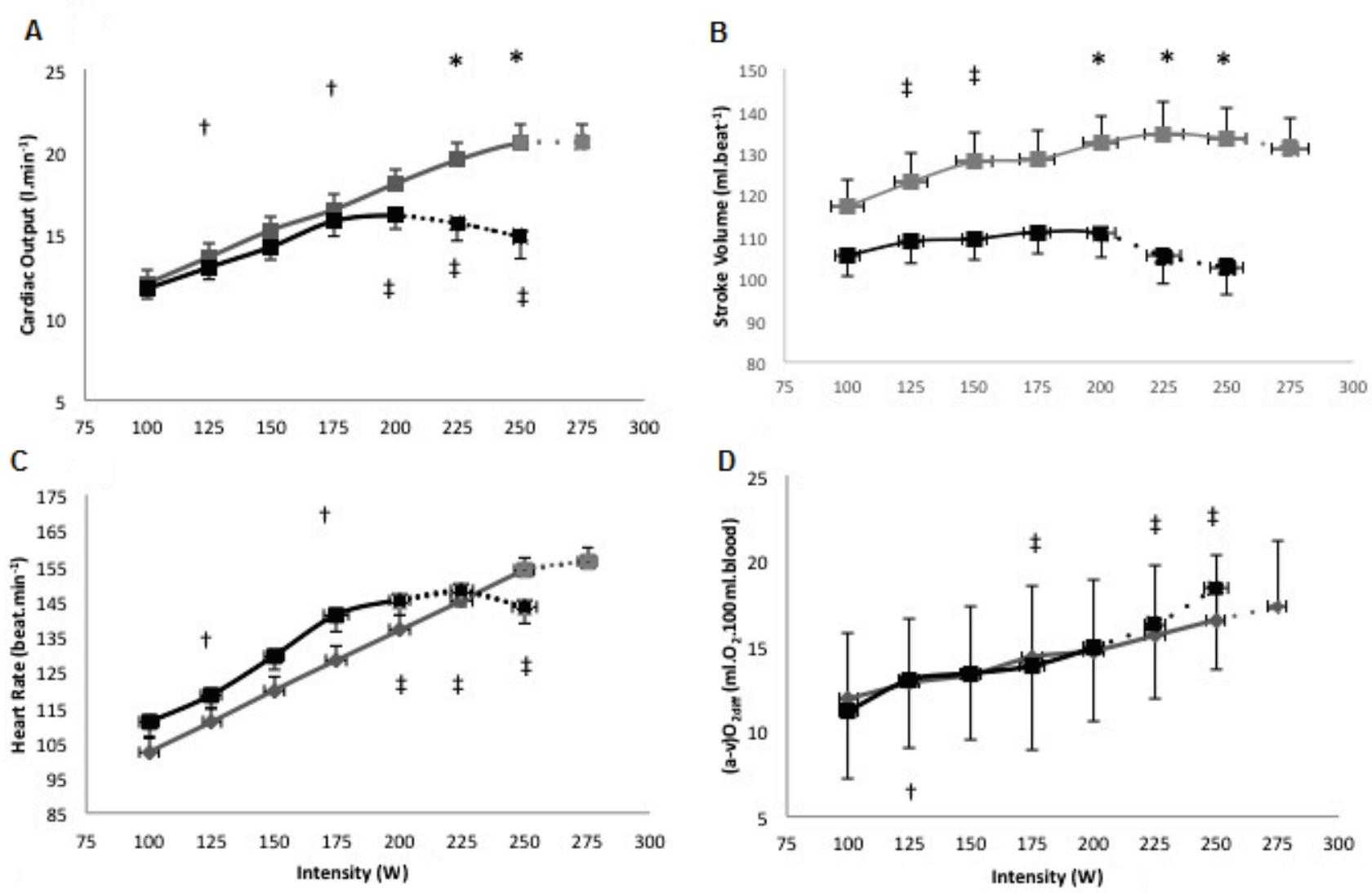

Fig. 1. Cardiac output (A), stroke volume (B), heart rate $(\mathbf{C})$, and $(a-v) \mathrm{O}_{2 \text { diff }}(\mathbf{D})$ responses to incremental to maximal cycling exercise in recreational athletes (gray lines) and leisurely active older men (black lines). Significantly different $(p<0.05) *$ between groups, ₹ within recreational athletes and + within leisurely active older men. Number of subjects who completed each workload by group:

\begin{tabular}{lllllllll}
\hline Workload (W) & $\mathbf{1 0 0}$ & $\mathbf{1 2 5}$ & $\mathbf{1 5 0}$ & $\mathbf{1 7 5}$ & $\mathbf{2 0 0}$ & $\mathbf{2 2 5}$ & $\mathbf{2 5 0}$ & $\mathbf{2 7 5}$ \\
\hline Recreational athletes & 15 & 15 & 15 & 15 & 15 & 15 & 15 & 13 \\
Leisurely active older men & 13 & 13 & 13 & 12 & 11 & 7 & 5 & NA \\
\hline
\end{tabular}

$\mathrm{VO}_{2 \max }$ was significantly different between groups. VT occurred at $75 \%$ of $\mathrm{VO}_{2 \max }$ (range: $51-88 \%$ ) in the RA and $72 \%$ of $\mathrm{VO}_{2 \max }(52-88 \%)$ in the LA $(\mathrm{p}=0.4)$. However, the absolute $\mathrm{VO}_{2}$ at $\mathrm{VT}$ was significantly different between groups (RA: $2.6 \mathrm{l} / \mathrm{min}$; LA: $1.8 \mathrm{l} / \mathrm{min} ; \mathrm{p} \leq 0.001)$. Additional data at VT and maximal exercise for both groups are available in Table 2. At VT and maximal exercise, $\mathrm{VO}_{2}, \mathrm{Q}$ and power (in W) were significantly higher in RA compared to LA. $\mathrm{SV}$ at VT was approaching significance $(\mathrm{p}=0.055)$ and was higher in the RA at maximal exercise $(\mathrm{p}=0.01)$. EDV was significantly higher in the RA at VT and was approaching significance at maximal exercise $(\mathrm{p}<0.01)$. No group differences were noted for HR or calculated (a-v) $\mathrm{O}_{2 \text { diff }}$ at any workload. At relative exercise intensities, between group differences in $\mathrm{Q}$ were observed across all intensities, except for $45 \%$. Differences observed in Q were largely attributed to differences in SV at these intensities, as HR only differed between groups at 70,90 , and $100 \%$ of maximal exercise.

SV increased by $15 \%$ in RA compared to $6 \%$ in the LA from $100 \mathrm{~W}$ to maximal exercise. There were increases in $\mathrm{Q}, \mathrm{HR}$ and (a-v) $\mathrm{O}_{2 \text { diff }}$ during incremental to maximal exercise within the LA and RA groups. SV in the RA group increased significantly during incremental to maximal exercise $(\mathrm{p}=0.02)$; however, no differences in SV were observed in the LA $(p=0.4)$. The SV, Q, HR, and calculated (a-v) $\mathrm{O}_{2 \text { diff }}$ profiles are displayed in Figure 1. SV was significantly higher in the RA compared to LA at maximal exercise and across most submaximal exercise intensities. SV increased at $30 \% \mathrm{VO}_{2 \max }$ compared to $25 \% \mathrm{VO}_{2 \max }(\mathrm{p}=0.03)$ and appeared to 
increase again at $45 \% \mathrm{VO}_{2 \max }$ compared to $40 \% \mathrm{VO}_{2 \max }$ $(p=0.06)$ in the RA.

\section{Discussion}

The primary finding of this study is that RA appear to have a more dynamic SV response during exercise than LA. Among the RA, SV plateaued at 30$45 \%$ of maximal exercise, while the LA had no change in SV throughout exercise. The secondary finding is that among a matched sample of older men, higher cardiorespiratory fitness in RA is primarily due to a greater central response (i.e., $\uparrow \mathrm{SV}$ ), as the peripheral response (i.e., a-vO $\mathrm{v}_{2 \text { diff }}$ ) between $\mathrm{RA}$ and LA appears to be the same. This novel investigation fills a gap in current knowledge pertaining to the cardiovascular response to maximal exercise testing in non-endurance trained and non-sedentary older men.

Our findings are the first, to our knowledge, to compare the cardiovascular response to maximal cycling exercise in recreationally active older men. We observed a SV plateau between $30-45 \%$ of maximal exercise in the RA, similar to what has been previously reported in highly trained older adults. Specifically, in a study of older endurance trained male runners and cyclists, (i.e. those who had trained consistently for at least 3 years and who routinely ran a minimum of $>30 \mathrm{~km}$ per week) participants completed an exercise test on a cycle ergometer to volitional exhaustion. A plateau in SV was observed at approximately $40 \%$ of $\mathrm{VO}_{2 \max }$ in the runners and $30 \%$ of $\mathrm{VO}_{2 \max }$ in the cyclists (McLaren et al. 1997). Endurance trained men and master endurance trained runners (age: 51-72 years) can progressively increase SV up to the point of $70 \%$ and $85 \%$ of $\mathrm{VO}_{2 \max }$, respectively (Proctor et al. 1998, Rivera et al. 1989). Thus, training level (i.e. highly trained versus recreational athlete versus recreationally active) appears to have a significant impact on the cardiovascular response to maximal exercise among older adults as well.

Visually, a second increase in SV appeared after the initial plateau at $65 \%$ of $\mathrm{VO}_{2 \max }$ in the $\mathrm{RA}(\mathrm{p}=0.15$ NS). This observation is of particular interest, as the bulk of the research investigating such an increase in SV has primarily focused on young highly trained adults. There is some evidence that such an increase may occur in moderately active adults aged 18-30 years, but no such data are available in older men. From data on middleaged men with moderate fitness levels, it appears that the dominant response of SV to maximal exercise is a plateau followed by a subsequent decrease in SV (Ferguson et al. 2011, Skof and Milic 2012). A study by Skof and Milic (2012) examined the SV response to maximal exercise in a group of middle-aged men who were either highly trained runners $\left(\mathrm{VO}_{2 \max }: 54.1 \pm 3.8 \mathrm{ml} / \mathrm{kg} / \mathrm{min}\right)$ or moderately trained runners $\left(\mathrm{VO}_{2 \max }\right.$ : $36.8 \pm$ $3.3 \mathrm{ml} / \mathrm{kg} / \mathrm{min})$. The highly trained group exhibited higher $\mathrm{VO}_{2 \max }, \mathrm{Q}$, and $\mathrm{SV}$, similar to the present study. Skof and Milic (2012) also noted various responses in SV in both groups: a plateau, a plateau with a subsequent drop, a progressive increase, and a plateau with a significant decrease (in the highly trained group). Our data indicate that an increase may be possible in older men who are RA as well.

The higher SV observed in the more trained groups among previous studies may be related to a higher EDV. In the present study, EDV was greater in the RA at VT and approaching significance at maximal exercise compared to the LA; however EDFR was not. A study comparing older trained and sedentary adults using Doppler echocardiographic data found no differences in left ventricular diastolic filling characteristics except for a trend for atrial filling fraction (Jungblut et al. 2000). Similarly, Carrik-Ranson et al. (2012) did not find differences in left ventricle filling or lengthening when comparing younger and older men. In other words, it seems that preload may not be predicting differences in SV among older men, but rather factors such as blood volume or ventricular contractility and autonomic response may be. Future research is needed to determine which factors are leading to differences in SV among older men and to confirm the possibility of an increase in SV after the initial plateau. Nevertheless, the present finding offers interesting insight into cardiovascular aging and lifelong exercise engagement.

The observation that differences in $\mathrm{VO}_{2 \max }$ were exclusively due to differences in central components between groups was of significant interest. Research by Murias et al. (2011) showed that older men who engaged in a 12 week aerobic training program on a cycle ergometer were able to increase $(\mathrm{a}-\mathrm{v}) \mathrm{O}_{2 \text { diff, citrate }}$ synthase and capillarization. As such, it was expected that the RA group in the present study would have a higher calculated (a-v) $\mathrm{O}_{2 \text { diff }}$ than the LA. Evidence from crosssectional studies of men and women support the findings of the present study in that they have also noted reliance on central components and no differences in peripheral components between trained and untrained groups (Proctor et al. 1998, Dogra et al. 2012). Specifically, in 
a study by Sagiv et al. (2007), 15 older aerobically trained $\left(\mathrm{VO}_{2 \max }: 42.1 \pm 2.1 \mathrm{ml} / \mathrm{kg} / \mathrm{min}\right)$ and 15 older untrained $\left(\mathrm{VO}_{2 \max }: 31.1 \pm 2.4 \mathrm{ml} / \mathrm{kg} / \mathrm{min}\right)$ men underwent a maximal exercise test on a cycle ergometer. The trained group exhibited greater reliance on central components of cardiorespiratory fitness; similar oxygen extraction was noted in both trained and untrained groups (Sagiv et al. 2007). This discrepancy in (a-v) $\mathrm{O}_{2 \text { diff }}$ between crosssectional and laboratory based intervention research requires further investigation as it may 'shed light' on important methodological limitations or physiological mechanisms associated with the aging process.

The present study utilized technology that enabled continuous measurement of SV. This may have allowed for more accurate identification of a peak in both our RA and LA groups as well as the identification of a second increase in SV. Previous research has primarily used methods such as acetylene wash in, which assesses $\mathrm{Q}$ and SV at predetermined workloads only (Dogra et al. 2012). The continuous measurement of $Q$ was a significant strength of this study. Limitations of the present study were the lack of direct measurement of

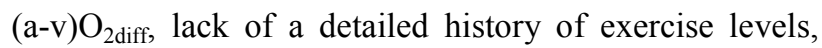
and the cross-sectional study design. Future research should make use of technology such as near infra-red spectroscopy to better understand the physiological responses of muscle oxygen extraction.

\section{Conclusions}

In conclusion, it appears that a higher cardiorespiratory fitness in older aerobically active men (RA) is due primarily to a higher Q, specifically SV, when compared to LA older men. Of note, the present findings suggest a secondary increase in SV may be possible in RA whereas, the SV response in the LA remains unchanged during incremental to maximal exercise. These findings provide novel insight into the cardiovascular response to incremental cycling exercise among non-elite and non-sedentary older men.

\section{Conflict of Interest}

There is no conflict of interest.

\section{References}

ASTRAND PO, CUDDY TE, SALTIN B, STENBERG J: Cardiac output during submaximal and maximal work. J Appl Physiol 19: 268-274, 1964.

CANADIAN SOCIETY FOR EXERCISE PHYSIOLOGY: Physical Activity Readiness Questionnaire. 2013.

CARRICK-RANSON G, DOUGHTY RN, WHALLEY GA, WALSH HJ, GAMBLE GD, BALDI JC: Larger exercise stroke volume in endurance-trained men does not result from increased left ventricular early or late inflow or tissue velocities. Acta Physiol (Oxf) 205: 520-531, 2012.

CHARLOUX A, LONSDORFER-WOLF E, RICHARD R, LAMPERT E, OSWALD-MAMMOSSER M, METTAUER B, GENY B, LONSDORFER J: A new impedance cardiograph device for the non-invasive evaluation of cardiac output at rest and during exercise: comparison with the "direct" Fick method. Eur J Appl Physiol 82: 313-320, 2000.

DOGRA S, SPENCER M, PATERSON D: Higher cardiorespiratory fitness in older trained women is due to preserved stroke volume. J Sports Sci and Med 11: 745-750, 2012.

FERGUSON S, GLEDHILL N, JAMNIK VK, WIEBE C, PAYNE N: Cardiac performance in endurance-trained and moderately active young women. Med Sci Sports Exerc 33: 1114-1119, 2001.

JUNGBLUT PR, OSBORNE JA, QUIGG RJ, MCNEAL MA, CLAUSER J, MUSTER AJ, MCPHERSON DD: Echocardiographic Doppler evaluation of left ventricular diastolic filling in older, highly trained male endurance athletes. Echocardiography 17: 7-16, 2000.

MCLAREN PF, NURHAYATI Y, BOUTCHER SH: Stroke volume response to cycle ergometry in trained and untrained older men. Eur J Appl Physiol 75: 537-542, 1997.

MURIAS JM, KOWALCHUK JM, RITCHIE D, HEPPLE RT, DOHERTY TJ, PATERSON DH: Adaptations in capillarization and citrate synthase activity in response to endurance training in older and young men. J Gerontol A Biol Sci Med Sci 66: 957-964, 2011.

PATERSON D, WARBURTON D: Physical activity and functional limitations in older adults: a systematic review related to Canada's Physical Activity Guidelines. Int J Behav Nutr Phys Act 7: 38, 2010. 
PROCTOR DN, BECK KC, SHEN PH, EICKHOFF TJ, HALLIWILL JR, JOYNER MJ: Influence of age and gender on cardiac output- $\mathrm{VO}_{2}$ relationships during submaximal cycle ergometry. J Appl Physiol 84: 599-605, 1998.

RICHARD R, LONSDORFER-WOLF E, CHARLOUX A, DOUTRELEAU S, BUCHHEIT M, OSWALDMAMMOSSER M, LAMPERT E, METTAUER B, GENY B, LONSDORFER J: Non-invasive cardiac output evaluation during a maximal progressive exercise test, using a new impedance cardiograph device. Eur J Appl Physiol 85: 202-207, 2001.

RIVERA A, PELS A, SADY S, SADY M, CULLINANE E, THOMPSON P: Physiological factors associated with the lower maximal oxygen consumption of master runners. J Appl Physiol 66: 949-954, 1989.

SAGIV M, GOLDHAMMER E, BEN-SIRA D, AMIR R: What maintains energy supply at peak aerobic exercise in trained and untrained older men? Gerontology 53: 357-361, 2007.

SKOF B, MILIC R: Stroke volume dynamics in male subjects of different fitness levels. Kinesiologia Slovenica 18: 5$13,2012$.

VELLA C, ONTIVEROS D, ZUBIA R: Cardiac function and arteriovenous oxygen difference during exercise in obese adults. Eur J Appl Physiol 111: 915-923, 2011. 